\title{
The effects of drama-based activities as a language learning tool on learners' motivation in Non-Malay- medium national schools in Malaysia
}

\author{
Chang Fui Man, Sabariah Sharif*, Andrea Lee Jen May, Rosy Talin, and \\ Soon Singh Bikar Singh \\ Education Department, Faculty of Psychology and Education, \\ Universiti Malaysia Sabah (UMS), Jalan UMS, 88400, Kota Kinabalu, Sabah, Malaysia
}

\begin{abstract}
Transitioning from Non-Malay-medium national primary schools to Malay-medium or Englishmedium secondary schools proved to be a struggle for many students due to the lack of emphasis on audio-lingual skills of the second language (L2) throughout their six-years of primary education. This study aims to explore the effects of drama-based activities as a language learning strategy on L2 learning motivation among students aged between 12 to 13 years old from Non-Malay-Medium National Schools. Six students were recruited through purposive sampling to participate in this qualitative experimental research. Over a period of 14 weeks, pre-intervention interviews (on the first week), intervention (over the span of 2 hours per week for 12 weeks), and post-intervention interviews (on the fourteenth week) were carried out. The content of the intervention was adapted from the Trinity College London's Grade 4 Communication Skills syllabus. The instruments used for data collection include:(1) predetermined pre-and post-intervention interview protocols and (2) classroom observation rubric. Two themes emerged in the analysis of this study: (a) language learning motivation and (b) affective filter. Findings revealed that participants were motivated and possessed selfconfidence in the language learning process. The current study provides instructional implications for instructors and learners besides contributing to the novelty in the area of the research setting and sampling for future studies.
\end{abstract}

Keywords: Drama-based activities; language learning motivation; learning tools; Non-Malaymedium national school; secondary school

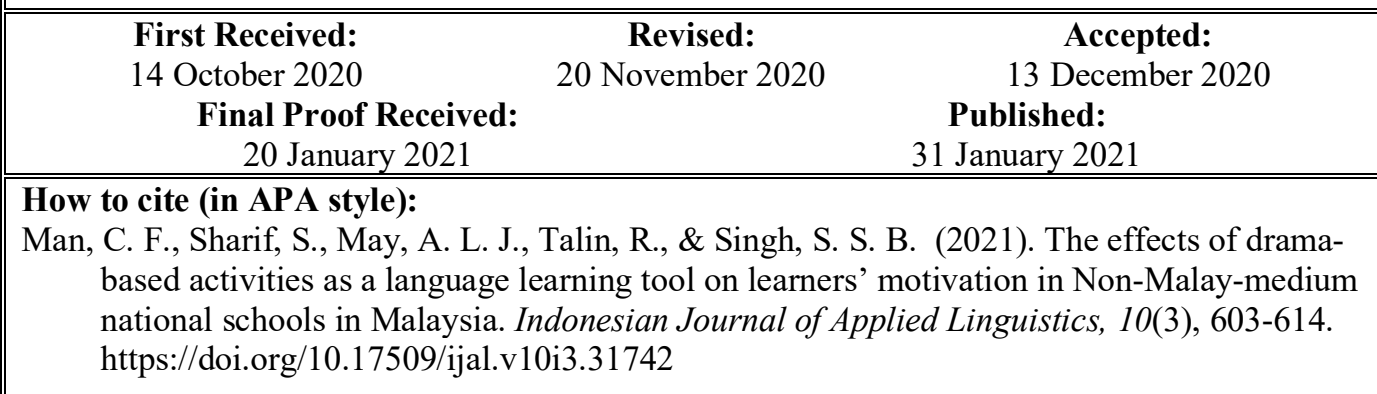

\section{INTRODUCTION}

A language holds a global status when its purpose is recognised in every country (Crystal, 2003). In line with this, English has gained a unique status among all known languages. Being known as a 'lingua franca' (Smit, 2010), a 'Global Language' (Crystal, 2003), 'International English' or 'Global English' (Francis \& Ryan, 1998), it is recognized as the language of business, science, technology,

*Corresponding Author

Email: sabariah@ums.edu.my education, the Internet, entertainment, as well as sports (Crystal, 2003; De Costa, 2009; Francis \& Ryan, 1998; Nunan, 2001; Smit, 2010). The importance of English does not only affect the exchange of information in different fields worldwide, but also the livelihood and job opportunities of fresh graduates in Malaysia. Poor command of English was listed as one of the top five factors of the rising unemployment rate among 
fresh graduates in Malaysia (Malaysia Kini, 2017; Malay Mail Online, 2016; Jobstreet Malaysia, 2015).

Different mediums of instructions are used in different levels of education system in Malaysia. For example, Malaysia's public primary schools can be classified based on the medium of instruction: (1) Malay-medium National Schools (Sekolah Kebangsaan, SK) and (2) Non-Malay-medium National Schools (Sekolah Jenis Kebangsaan, SJK). At primary level, non-language subjects such as Science, Mathematics, Geography and History, though having the same syllabus, these lessons are conducted using different language mediums depending on either type of National Schools.

Although Malay and English languages are compulsory subjects in all schools, both languages are treated as a Foreign Language whereby the language acquisition process occurs only during the few hours of lessons per week. Both languages taught only involve the syntactical structures, focusing on honing students' reading and writing skills in order to fulfil said academic requirements. Hence, students consistently lacked in performance in the other two remaining language skills listening and speaking - due to limited opportunity to practise at this stage. Hence, it is not surprising if students struggle to cope with their academic performance when they enter into secondary education of different language medium of instructions, be it English or Bahasa Malaysia.

Drama has emerged as an effective method which involves the participation of both, teachers and students, during the entire learning process, presenting the target language to learners in "an interactive, communicative and contextualized way" (Mattevi, 2005, as cited by Albalawi, 2014). Although the use of drama is proven to be a valuable L2 teaching strategy and is increasingly common in the educational contexts (Albalawi, 2014; Greenfader et al., 2015; Javid, 2013; Kalidas, 2014; Papadopoulos, 2014; Rew \& Moon, 2013), many teachers remain sceptical of this innovative strategy. This is due to various concerns such as losing class control, noise level, time constraint, and the fear of being unable to achieve their learning outcomes (Kalidas, 2014). However, it is important to note that well-structured activities such as drama allow students to not only enjoy the learning process, but at the same time, develop their creativity, reasoning, and interpersonal skills (Kalidas, 2014).

There are studies which have been conducted in Malaysia, though limited, on the effectiveness of applying drama as a learning tool in relation to confidence level and creative thinking among students. However, the participants selected were secondary students and undergraduates of which different research methodology was employed (Abdullah \& Mukhtarudin, 2010; Kalidas, 2014;
Nawi, 2014; Nordin et al., 2012). As for primary level students in Kota Kinabalu, Sabah, there are limited quantitative research in this area.

Learners' motivation plays a predominant role in the L2 learning process (Al Rifai, 2010; Mahadi \& Jafari, 2012; Nzanana, 2016). One of the earliest L2 motivation theories is developed by the Canadian social psychologists, Robert Gardner, Wallace Lambert and their colleagues. Gardner's Motivation Theory considered motivation as a primary driving force in the L2 learning process. Motivation is defined as the degree of effort an individual give in an attempt to learn the desired language as well as the fulfilment one experienced throughout the process (Gardner, 1985). Gardner proposed the instrument known as the Attitude/Motivation Test Battery (AMTB) to measure learners' motivation via six variables of the socio-educational model affecting the L2 learning process. This instrument is widely used by educational researchers when investigating learners' motivation in the learning of L2 (Cocca et al., 2017; Ghazvini \& Khajehpour, 2011; Nzanana, 2016; Orío, 2013). The socioeducational model encompasses variables such as (1) integrative-ness, (2) attitude towards learning situation, (3) motivation, (4) language anxiety, (5) instrumental orientation, and (6) parental encouragement (Gardner, 1985). In the context of L2 learning motivation, motivation consists of three components, namely motivational intensity, desire to learn the language, and attitude towards language learning (Gardner, 1985).

In the context of L2 learning, drama-based activities are often linked to learners' motivation in an ESL classroom. Motivation can be classified into two categories in relation to the learning of L2 as identified by Gardner (1985), namely instrumental motivation and integrative motivation. Instrumental motivation is regarded as an aspiration to obtain recognition academically or benefits economically through mastering L2. Learners are driven by the desire to increase their occupational or business opportunities, obtaining more power and prestige (Wimolmas, 2012). In contrast, integrative motivation refers to the desire of the learners to be a representative individual of the L2 community (Gardner, 1985). As elucidated by Saville-Troike (2006), learners are motivated to learn the language due to the desire to want to socialise with target language speakers and to integrate into the community that speaks the target language. While students these days possess their personal perceptions and reasons as to why they are motivated to learn L2, their motivations can be classified into these two categories of motivation (Al Rifai, 2010; Ghazvini \& Khajehpour, 2011; Wimolmas, 2012).

Numerous research on learners' language learning motivation has been conducted where Gardner's (2004) Attitude- Motivation Test Battery 
(AMTB) has been widely used by researchers to measure learners' motivation in L2 learning. One such study is by Nzanana (2016), who conducted a mixed-method research on a group of undergraduates as well as teachers from the University of Rwanda to investigate the relationship between language learning motivation and L2 oral proficiency. Through the interview sessions with the teachers, it was discovered that though students were generally motivated to learn L2, there was a lack of emphasis in developing L2 speaking skills. This presents an issue from the standpoint of L2 oral proficiency development and motivation. The only way to improve oral proficiency is through engagement and participation with speaking activities (Lazaraton, 2014, as cited in Nzanana, 2016).

This study aims to explore the effectiveness of applying drama-based activities as a learning tool in increasing language learning motivation and level of confidence among students aged between 12 to 13 years old from Non-Malay-Medium National School. This study attempts to address the following research question:

1) What are the changes in students' language learning motivation after undergoing English lessons which are incorporated with drama-based activities as a language learning strategy?

\section{METHOD}

This qualitative research adopted the systematic design of the Grounded Theory Research Design. This research design aims to explore the common experiences as undergone by individuals to develop a theory. It focuses on collecting data through interview, developing and relating themes or categories generated from the collected data, analysing data using open, axial, and selective coding, followed by forming a visual paradigm of the theory generated from the data (Creswell, 2012).

The purposive sampling technique was employed in this study. Six school students aged between 12 to 13 years old from the Non-Malay Medium National School were selected for the intervention and pre- and post-intervention interview sessions.

The methodology for this study included the implementation of drama-based English syllabus, classroom observations, and interview sessions with the selected students. The group of participants met for two 2-hour lessons each week over a period of 12 weeks, which accumulated to a total of 24 hours of learning. This program adopted a communicative and task-based approach to language teaching and learning. A pre-intervention interview and postintervention interview were carried out separately with all participants where these interview sessions followed a pre-established interview protocol (see Table 1).

The data collected via interview sessions were transcribed, re-examined and analysed to identify the subcategories, categories and emerging themes to identify students' language learning motivation. As shown in Table 2, data analysis was done through the process of open coding, focused coding, axial coding and selective coding of the transcribed data.

An observation protocol was developed to assess the observable student behaviours during language learning to triangulate students' language learning motivation.

Table 1

An Overview of Data Collection Instruments

\begin{tabular}{lcl}
\hline Data Collection Phases & Methods \\
\hline Pre-Intervention Interview Session & $\bullet$ & Pre- intervention interview protocol \\
Intervention & - Drama-based activities incorporated lesson plans \\
& - Classroom observation protocol \\
Post- Intervention Interview Session & - Post- intervention interview protocol \\
\hline
\end{tabular}

Table 2

An Overview of the Data Analysis Methods

\begin{tabular}{ll}
\hline Data Types & Data Analysis Method \\
\hline Pre-Intervention Interview & Coding \\
Post-Intervention Interview & Coding \\
Post-Lesson Recorded Videos & Observation protocol \\
\hline
\end{tabular}

\section{Interview}

The interview questions were adapted from previously published research where the items were pre-determined before the interview sessions. Since this is a qualitative research, the open-ended approach was used, of which, mostly general questions were asked so that the interviewees' responses would not be restricted (Creswell, 2012). Similar to the application of observation protocol during observation, interview protocols were used during the interview sessions to record notes during the interview. The selected interview approach for the current study was the one-on-one interview. This implies that the researcher will only be interacting 
with a single participant in the session at a time. This type of interview allows participants to share their views comfortably since their privacy and confidentiality are guaranteed. Due to the nature of the research design, a pre-intervention interview and post-intervention interview were carried out separately for all participants.

\section{Drama-based activities as intervention}

The intervention requires the group of participants to attend two 2-hour lessons each week over a period of 12 weeks, which accumulated to a total of 24 hours of learning. The program implemented adopts a communicative and task-based approach to language teaching and learning.

The syllabus and supplementary materials were adapted from a published drama-based activities and materials of similar approaches and were revised to fit into the context of Malaysia's English education.

Triangulation and trustworthiness of data collection and data analysis

To increase the trustworthiness of the research, the data collected were triangulated using the methodological triangulation and investigator triangulation method. Methodological triangulation refers to the usage of multiple qualitative data collection methods to investigate the research questions, whereas investigator triangulation refers to the involvement of different investigators in the data analysis process (Carter et al., 2014; Guion et al., 2002).

\section{RESULTS}

Overall, there were two themes that emerged from the pre- and post-intervention interviews as well as from the video observation on students' language learning motivation: (a) language learning motivation and (b) affective filter.

\section{Pre-intervention interview data analysis}

Before intervention, there were only three categories and six subcategories which emerged from the preintervention interviews on student's language learning motivation: (a1) global language (extrinsic motivation and interpersonal communication (integrative motivation)), (a2) language proficiency (writing proficiency and oral proficiency), and (b1) emotional states (self-confidence and enjoyment).

\section{Global language - language learning motivation}

Participants expressed their opinions on the effectiveness of drama-based activities in English language learning and agreed that it is indeed an effective language learning strategy. Participant TG001 noted that through drama-based activities, "my teacher encourages me to speak more English and I tried to speak more English, so my English became more fluent." As his English performance improved academically, he was rewarded with a tangible item, which in turn "motivated me to perform well." On the other hand, Participant TG006 expressed that learning English through drama-based activities will allow him to make conversations with others in English. These are categorised under extrinsic motivation and interpersonal communication (integrative motivation) in the category of global language.

\section{Language proficiency - language learning motivation}

Both participants TG001 and TG002 agreed that through drama-based activities, they can "speak more fluently." Participant TG006 also added that writing skills may be improved as well through drama-based activities. These are categorised under oral proficiency and writing proficiency in the category of language proficiency.

\section{Emotional states - affective filter}

Participant TG002 highlighted the confidence to converse in English through the participation of drama-based activities by "joining a competition and able to speak confidently in front of a crowd" while participant TG006 was with the opinion that learning through drama-based activities is a "fun and interesting" way to improve his conversational English skills and writing skills. These are categorised under self-confidence and enjoyment in the category of emotional states.

\section{Post-intervention interview data analysis}

After intervention, there were five categories and thirteen subcategories which emerged from the postintervention interviews on student's language learning motivation: (a1) global language (intrinsic motivation, interpersonal communication (integrative motivation) and academic purposes (instrumental motivation)), (a2) language proficiency (writing proficiency and oral proficiency), (a3) language learning activities (book-based language learning activities, speaking activities and drama-based activities), (b1) language learning styles (peer learning and self-study) and (b2) emotional states (self-confidence, enjoyment and reduced anxiety).

\section{Global language - language learning motivation} All participants agreed that English is an international language. For example, participant TG001 noted that "learning English is important," while participant TG002 stated that "the global language is English." Moreover, participant TG006 also indicated the usage of English in other countries. These are categorised under intrinsic motivation in the global language category.

They were also in agreement that learning English is for the benefit of academic purposes (instrumental motivation of the category global language). For example, participant TG001 stated English will be "useful in the future when they go 
overseas for further studies because they use English in university." Participant TG002 added that learning English will "help with the main study because all the subjects will be taught in English at university level," and it will allow participants to "obtain necessary certificates or qualifications for work purposes".

Participants TG002 and TG006 also stressed on the interpersonal communication (integrative motivation of the category global language) of English usage. Participant TG002 stated that "without English, you can't really communicate with the others," and that "you can make more friends," because "people can understand you better," if communication can be done in English. Participant TG006 shared the same sentiment and noted that it is "easier to explain things in English" and "people can understand better if you speak English."

\section{Language proficiency - language learning motivation}

All the participants expressed their goals in language learning which is to achieve fluency in writing (writing proficiency of the category language proficiency) and fluency in speaking (speaking proficiency of the category language proficiency). Participant TG001 noted that he "doesn't wish to be too professional but wants to be able to talk and write more fluently in English." Participant TG002 stressed the desire to speak more fluently. Participant TG006 wished to "improve English" and "speak English" fluently.

\section{Language learning activities - language learning motivation}

There were three subcategories under the language learning activities category: book-based language learning activities, speaking activities and dramabased activities. Book-based language activities included writing activities, homework and using textbook and activity book in class. Speaking activities in class included speaking practices with the teacher and a compulsory oral test. Participants expressed interest in drama-based activities for language learning purpose. According to participant TG001, the drama-based activities promote interaction through games and "acting and cooperating with each other." Participant TG002 also noted that through drama-based activities one gets to "try out different activities," and the activities "are not bound by rules," allowing them to be creative at the same time.

\section{Language learning styles - affective filter}

There were two identified subcategories under the category of language learning styles, namely, selfstudy and peer learning. Self-study included the efforts made by the learners themselves. For example, participant TG001 will "do revision every Sunday or after school," whereas participant TG006 tried to read English novels. The subcategory peer learning was identified as the participants stressed on communicating with friends in English through drama-based activities. Participant TG001 noted that he can "learn from friends," because when he attempts to communicate or express himself in English, his peers and teacher will guide him by providing corrections and proper usage of words and phrases in English. Participant TG002 also expressed his effort in communicating with friends in English and "motivate friends to speak English."

\section{Emotional states aspect - affective filter}

There were three identified subcategories under the emotional-state category from the post-intervention interviews on the incorporation of drama-based activities as a learning strategy: self-confidence, reduced anxiety and enjoyment. Participant TG001 stated that he "showed some improvements in speaking" as his speech became more fluent. Participant TG06 noted that his improvement in speaking was also noticed by his parents. These are categorised under the subcategory of selfconfidence. Participant TG006 noticed the difference in his anxiousness when speaking and commented that he was "feeling nervous when I first joined the English lessons," and that he preferred speaking Chinese "because my English is not very good". This is categorised under the reduced anxiety subcategory. All participants expressed their enjoyment for the English lessons incorporated with drama-based activities. Participant TG001 was happy and did not feel bored throughout the lessons. Additionally, participant TG002 noted that he was happy to meet new friends and had fun "watching my friends interacting with each other in English." He also noted that he enjoyed being part of the lessons.

\section{Video observation analysis}

Participants' in-class behaviours were analysed to consider their language learning motivation based on observable behaviours. There were a total of nine observable behaviours during the English lessons. These are classified according to themes and categories as shown in Table 3.

From the video observation of the intervention, there were four categories and six subcategories which emerged from student's language learning motivation: (a1) global language (intrinsic motivation, extrinsic motivation and interpersonal communication (integrative motivation)), (a2) language learning activities (drama-based activities), (b1) language learning styles (peer learning) and (b2) emotional states (enjoyment). 
Table 3

Observed Behaviors of In-class Participants

\begin{tabular}{|c|c|}
\hline Themes & Categories / Sub-Categories / Observable Behaviors \\
\hline \multirow{10}{*}{$\begin{array}{l}\text { Language } \\
\text { Learning } \\
\text { Motivation }\end{array}$} & Global Language \\
\hline & Intrinsic Motivation \\
\hline & $\begin{array}{ll}\text { - } & \text { Students showed an interest in the activity. [Also showed elements of Enjoyment] } \\
\text { - } & \text { Students asked questions in English. }\end{array}$ \\
\hline & $\begin{array}{l}\text { Extrinsic Motivation } \\
\text { - } \quad \text { Students made an effort to complete the task. }\end{array}$ \\
\hline & $\begin{array}{cc}\text { Interpersonal Communication (Integrative Motivation) } \\
\quad \text { Students communicated with each other in English. }\end{array}$ \\
\hline & Language Learning Activities \\
\hline & Drama-Based Activities \\
\hline & - $\quad$ Students understood and performed the task. \\
\hline & - $\quad$ Students presented the outcome of the task. \\
\hline & - $\quad$ Students made an effort to communicate ideas in English. \\
\hline \multirow[t]{4}{*}{ Affective Filter } & Language Learning Styles \\
\hline & Peer Learning \\
\hline & - $\quad$ Students completed the task in pairs / group. \\
\hline & - $\quad$ Students communicated with each other when performing the task. \\
\hline
\end{tabular}

Global language - language learning motivation Participants showed interest in the activities during the intervention. For example, participant TG002 showed great interest in activities, displaying exciting facial expressions when the teacher revealed the materials to be used during the intervention activity. Participant TG001 also portrayed similar behaviour during the intervention. As for participant TG006, this particular participant showed interest through his attentiveness when the instruction was given during the intervention. He responded immediately by completing the activity instantly. Participants were also actively asking questions in English during the intervention. Participant TG002 frequently asked questions with regards to the activities in English. Participants TG006 and TG001 also portrayed similar behaviour during the intervention but of lesser frequency as compared to participant TG002. Both the observable behaviours are categorised under the subcategory of intrinsic motivation.

Participants also attempted to communicate ideas, opinions or thoughts in English in order to complete the activities during the intervention. For example, as a result of the teacher's frequent reminder and encouragement in communicating only in English, participants TG002 and TG006 frequently expressed their thoughts and exchange opinions in English. Participant TG001 also tried to communicate in English throughout the intervention but of lesser frequency. This observable behaviour is categorised under the extrinsic motivation subcategory.

The participants also communicated in English throughout the intervention as compared to the initial phase when they tended to communicate in Chinese (first language of the participants). For example, participant TG002 communicated in
English frequently with other participants even on topics that were unrelated to the planned activities. Participant TG006 and TG001 also showed similar behaviour during intervention but of lesser frequency compared to participant TG002. It was recorded that they were chatting about games and getting to know each other in English. This is categorised under the subcategory of interpersonal communication.

\section{Language learning activities - language learning motivation}

The researchers noted that the participants understood and performed the task as per the instructions given by the teacher. During the intervention, there were two types of task assigned to the participants, a group task and an individual task. Overall, participants TG002 and TG006 portrayed higher frequency of this behaviour although there was a slight difference between the two participants. Participant TG002 showed an understanding of the task and proceeded to perform the task although he was distracted from time to time, engaging in conversation with other participants. Meanwhile, participant TG006 showed a more introverted characteristic and was more immersed in task completion. As for participant TG001, the frequency of the behaviour was less compared to the other participants. Participant TG001 showed a more easily influenced characteristic where he gets distracted by joining in conversations with the others. All participants were also constantly trying to complete the task throughout the intervention. The efforts of the participants in completing the task include taking the initiative to ask questions, writing notes based on the topic given, making corrections on their work after being evaluated by the teacher and presenting 
the outcome of the task. Participant TG006 showed the highest frequency in trying to complete the task. Participants TG002 and TG001 also showed similar behaviour but of a lesser frequency. Participants were monitored in presenting the outcome of the task during group activities. The participants were divided into two groups to present the outcome of the task. Both participants TG002 and TG001 were grouped whereas TG006 was placed in another group. Participant TG006 was seen taking part in presenting the outcome of the task for his group. Meanwhile, participant TG002 was seen to represent his group in presenting the outcome of the task. These observable behaviours are categorised under the subcategory of drama-based activities.

\section{Language learning styles - affective filter}

Through the observation of the researchers, the participants are more likely to complete tasks in a group. This behaviour was monitored in all three participants. The participants also discussed with each other during the task in order to have a mutual understanding and reach a conclusion. Participant TG002 showed the highest frequency in engaging with his peers while performing the task by frequently voicing out his opinions. Both participants TG006 and TG001 showed a lesser frequency of such behaviour but their overall engagement with their peers was deemed to be significant enough in task completion. Both these observable behaviours are categorised under the peer learning subcategory.

\section{Emotional states - affective filter}

The observable behaviours of the participants demonstrating interests in activity that was initially categorised under the intrinsic motivation subcategory (of the global language category and language learning motivation theme) also depicted elements that can be categorised under the subcategory of enjoyment.

\section{DISCUSSION}

Findings from the pre- and post-intervention interviews, as well as video observations, confirmed two themes which emerged on students' language learning motivation after utilising drama as a language learning strategy, namely (a) Language Learning Motivation (with the inclusion of categories Global Language, Language Proficiency and Language Learning Activities) and (b) Affective Filter (with the inclusion of Language Learning Styles and Emotional States). This suggests a new insight into the language learning motivation theory.

Previous findings and theories discussed the terms, Language Learning Motivation and Affective Filter strictly based on their definitions and presented them as separate or interacting factors throughout students' language learning journey.
Such presentation of the terms contradicted with the current findings in which the two themes are viewed as equally important factors in influencing students' language learning motivation.

Past studies on language learning motivation focused solely on the types and levels of learning motivation in students' language learning journey. Among these studies was a quantitative research conducted by Gonzales and Lopez (2015) which aimed to assess the different types of foreign language learning motivation among 640 college students from private and public universities in the Philippines. The revised six factors and 40-item Foreign Language Learning Motivation Questionnaire for Filipinos (FLLMQ- F) questionnaire used in the study were categorised into two types of motivation, integrative motivation and instrumental motivation.

Gardner (1982) defined the term "students" motivation" as consisting of three elements: (i) effort (the time spent on studying), (ii) desire (the aspiration to achieve higher language proficiency) and (iii) affect (the emotional states while learning) (Carrió-Pastor \& Mestre, 2014). Krashen (1982) further developed the implication of these affective factors in foreign language learning process and formulated the Affective Filter Hypothesis (Ni, 2012). The affective factors include certain types of emotions, motivation, self-confidence and anxiety, all of which can impact the filter that either promote or prevent second language acquisition.

However, there are gaps in relation to the concept of affective filter: (1) Krashen's (1982) Affective Filter Hypothesis did not specify the types of motivation that could influence the affective filter, and (2) there are limited studies on the effect of affective filter on second language learning and learning motivation. Hence, Ni (2012) conducted a quantitative research among 50 university students from China to investigate the effects of affective factors (motivation, self-confidence and anxiety) on their language learning. It was found that the affective filter does indeed play an influential role in language acquisition and learning.

The themes Language Learning Motivation and Affective Filter which emerged from the findings of the current study address these gaps and will be further discussed in the following sections:

\section{Language learning motivation}

Findings from the current study suggested that the theme Language Learning Motivation can be further divided into three categories: (a1) Global Language, (a2) Language Proficiency and (a3) Language Learning Activities. The category of Global Language includes four types of learning motivation: intrinsic motivation, extrinsic motivation, interpersonal communication (integrative motivation) and academic purposes (instrumental motivation). It was indicated that the 
participants' main reason of learning the English language was because English is seen as an international language used globally. Hence, whether it is to further their study or to communicate with other English speakers, the participants are motivated to learn the language. The types of language learning motivation were not only limited to integrative motivation and instrumental motivation as investigated by previous studies but also includes both extrinsic motivation and intrinsic motivation. This was evident when one of the participants was motivated by tangible rewards from his parents. Moreover, participants showed interest in performing tasks that facilitated language learning and such behaviour is classified under intrinsic motivation.

There are many studies conducted to investigate the type of learning motivations in Second Language Acquisition. The findings on language learning motivation in this study are supported by the works of Smet (2016), CarrióPastor and Mestre (2014), and Wimolmas (2012). Smet's (2016) experimental quantitative study on the relationship between learning motivations and L2 oral proficiency among a group of 120 Dutch high school students in the Netherlands found that there is a positive correlation between integrative motivation and second language oral proficiency. An experimental study on the types of language learning motivation among university students in Spain conducted by Carrió-Pastor and Mestre (2014) reported similar findings. This implies that integrative motivation can sustain long-term success in second language learning. Furthermore, Wimolmas' (2012) quantitative research on a group of first-year university students in Thailand concluded that the respondents had a high degree of instrumental and integrative motivation towards English language learning.

Language proficiency in both writing and speaking also served as a language learning motivation factor as it is the end goal that participants aim to achieve from their language learning journey. Hence, Language Proficiency is categorised under the theme of Language Learning Motivation and is seen as a motivating factor for participants to learn English. This finding contradicts with the results of a quantitative research by Samad et al., (2012) and Lee and Oh (2011) where they viewed language proficiency as the effect of relying on language learning motivations.

Another category in relation to the theme of Language Learning Motivation is Language Learning Activities. From the intervention and postintervention interviews, participants discovered another new language learning activity apart from the conventional book-based language learning activities and speaking activities, the drama-based activities. Some participants found the conventional book-based language learning activities to be less interesting, knowing full well that it will be useful in expanding their knowledge of the language. Participants also noted that even though there are some existing speaking activities in their language classrooms, they are limited to only communicate with each other during the lesson about the topic taught by the teacher or with their teacher only. However, it was noted from the participants' interaction during the intervention that they were able to converse with each other in English, either to complete the tasks assigned by the teacher or to discuss other interests such as the types of games they like to play. They were also intrigued by the tasks assigned by the teacher throughout the course of intervention as the delivery of materials and the drama-based tasks are different from what they are accustomed to.

The usage of drama-based activities in an ESL classroom has been proven to be an effective learning tool (Iamsaard \& Kerdpol, 2015; Tavares, 2016). A mixed methodology experimental research conducted by Iamsaard and Kerdpol (2015) among eleventh graders in Thailand found that participants responded positively to the intervention of drama activities. The researchers utilised lesson plans adapted from Davie (1990) to improve participants' English-speaking skills. From the questionnaire distributed, it was found that (1) the dramatic activities allowed the participants to participate and learn the language while having fun at the same time, and (2) the difficulty level of the activities was appropriate for the participants which aid their understanding better and maintain their interests for the lessons (Iamsaard \& Kerdpol, 2015). Another quantitative study that uses drama-based activities as a learning tool for students' development in English oral proficiency also found that there are favourable changes in students' oral proficiency motivation after students were given drama activities as a strategy for language learning (Man et al., 2019).

\section{Affective filter}

The theme affective filter can be divided further into two categories: (b1) language learning styles, and (b2) emotional states. From the intervention and post-intervention interviews, participants discovered another language learning style which is peer learning. The subcategory of peer learning is supported by the findings of Thornton (2015) and Flanigan (1991).

The peer learning subcategory is interpreted as peer interaction in Tavares' (2016) study. The term peer interaction is defined as any communicative activities carried out between two or more learners working collaboratively towards a common learning goal with limited or zero participation from the teacher (Tavares, 2016; Philip et al., 2014). The current study shares a similar understanding of the peer learning subcategory. Flanigan's (1991) 
focused on the student-student interaction, also termed as peer tutoring, in an ESL classroom among 6 peer pairs. Her research investigated how L2 speakers with higher proficiency would use English during tutoring sessions with new learners. The findings of her qualitative research showed that L2 learners were able to obtain linguistic input from both native and non-native proficient L2 speakers (Flanigan, 1991). These findings supported the findings of the peer learning subcategory in which participants are said to have found a more interactive way of learning the language.

Students' emotional states are often disregarded during learning especially in the literature revolving around the Second Language Acquisition. This sentiment is supported by Schutz and Pekrun (2007) when they commented on the slow emergence of inquiry on the role of emotions in the educational contexts. Most researchers are more focused on students' text anxiety rather than the overall negative and positive emotions of the students and teachers in language learning.

The category, emotional states, was developed based on the analysis of data collected from the participants. The category emotional states included three subcategories: enjoyment, self-confidence and reduced anxiety. According to Schutz and Pekrun (2007), enjoyment and self-confidence are classified under pleasant emotions, whereas anxiety is classified under unpleasant emotions. Citing Krashen's (1982) Affective Filter Hypothesis, these subcategories are listed among the variables of the terminology Affective Filter from Krashen's hypothesis (Alawi, 2016).

The findings on the subcategory of enjoyment are supported by Dewaele and MacIntyre's (2016) findings on the effect of enjoyment in the English classroom on language mastery. Dewaele and MacIntyre (2016), citing Green (1993) noted in their study that there are limited studies with regards to the possible relationships between reported enjoyability by the students and the perceived effectiveness of learning techniques and activities. The mixed methodology research conducted by Dewaele and MacIntyre (2016) among 1742 welleducated respondents of a wide age range on the classification of Foreign Language Classroom Anxiety (FLCA) and Foreign Language Enjoyment (FLE) had led to the discovery of three factors: (1) FLCA, defined by the social apprehension, uneasiness as well as physical expressions of anxiety in the language classroom, (2) FLE-Social, defined by the positive feelings, peer encouragement, nice teachers and a supportive learning environment, (3) FLE-Private, defined by the positive thoughts and feelings along with a sense of achievement. Relating Dewaele and MacIntyre's (2016) findings to the results of the current study, the subcategory of enjoyment includes (1) factor FLE-Social as the participants expressed their enjoyment of the drama-based activities during the intervention and expansion of social circle, and (2) factor FLE-Private as the participants also saw their improvement in speaking proficiency as well as selfconfidence, supporting the findings on the selfconfidence subcategory.

On the other hand, the findings of the subcategory of reduced anxiety are supported by the studies of Alawi (2016). Alawi (2016) conducted a case study via mixed research methodology involving a six-year-old boy as well as his parents and teachers in the Philippines to investigate the degree of facilitation or debilitation of learners' affective-psychological on language acquisition and learning. The researcher found that boy's apparent shyness and lack of self-confidence contributed to his unwillingness to communicate in English although he had achieved a certain level of linguistic competence as indicated in the results of his written exams as well as from the researcher's interaction with the participant. Hence, it can be concluded that these variables have major effects on the process of second language acquisition and learning (Alawi, 2016).

\section{LIMITATION}

There were a few limitations which occurred in the course of this research. Firstly, due to limited resources, a digital voice recorder and a phone video recorder were used to record the interview sessions, and the same phone video recorder was also used to record the intervention English lessons. However, there were occurrences of technical error during the video recording of the intervention and postintervention interview sessions. Although the data from the interview sessions were provided for by the digital voice recorder, the loss of valuable data is irreplaceable. Hence, there should be at least three recording equipment to record the session to prevent the loss of valuable data for analysis.

Secondly, due to time constraint and limited human resources, the researcher's role in this qualitative research was of participant-as-observer where the researcher was fully engaged with the participants during intervention other than when administering the pre- and post-intervention interview sessions. It was noted by the investigator that there was a sense of familiarity between the participants with the researcher during the video observation analysis. The sense of familiarity with the researcher may potentially have some effect on participants' classroom engagement. They became more relaxed and inattentive at times throughout the lessons. Another factor contributing to their inattentiveness could be that the lessons were conducted during afternoons and on the weekends. The lessons were scheduled as such at the convenience of the students and parents as they are busy during weekdays and are generally more flexible during the weekends. 
Lastly, the room chosen to conduct the intervention was spacious and comfortable for the participants. However, the additional tripod for video recording purpose set up in the room may have taken up some space. Due to the nature of the classroom teaching which required the teacher to move around occasionally to monitor participant's work, the camera view was occasionally briefly blocked. The evaluation process may be inaccurate as the investigator was not able to identify the participants. Another tripod should be set up elsewhere in the classroom to assure that the activities in the classroom are well-captured from all angles.

\section{CONCLUSION}

Based on the findings, the participants which consisted of students aged between 12 to 13 years old confirmed that their motivation towards language learning is intrinsically linked to Global Language, Language Proficiency and Language Learning Activities. Language learning motivation that focuses on Global Language includes the four types of learning motivation: intrinsic motivation, extrinsic motivation, interpersonal communication (integrative motivation) and academic purposes (instrumental motivation). Results have shown that these types of motivation were evident when most participants knew how important it was for them to learn English as it is a language used to communicate globally. Another reason why the participants were motivated to learn English was so that they could receive a reward from their parents aside from having an interest in completing a task that would facilitate in their language learning. Meanwhile, some participants gained their motivation because of Language Proficiency, in which they have a desire and goal to be proficient in both writing and speaking. In addition to that, there were also participants who were driven by the Language Learning Activities. This can be seen when participants enjoyed learning English through the new drama-based activities as compared to how they would usually learn English via conventional methods. Participants were more excited and intrigued to learn English as the drama-based activity was something that they have never been done before.

The results of this study also suggest the possibility of expanding the research setting and sampling for further study. A wider scope of sampling may provide a better generalisation and development of the language learning theory on the usage of drama-based activities as a learning strategy in English oral proficiency development. Future studies can also be conducted with participants of different education levels to analyse the effectiveness of the usage of drama-based activities as a learning strategy in English oral proficiency across educational levels. The administration of the intervention sessions could also be extended to a longer period for a more significant result in terms of participants' oral proficiency performance.

\section{REFERENCES}

Abdullah, M. N., \& Mukhtarudin, M. N. (2010). Using Drama Activities as a Catalyst in Improving Communicative Confidence: A Case Study. Universiti Teknologi Malaysia Institutional Repository.

Al Rifai, N. (2010). Attitude, motivation, and difficulties involved in learning the English language and factors that affect motivation in learning it. Procedia - Social and Behavioral Sciences, 2(2), 5216-5227. https://doi.org/10.1016/j.sbspro.2010.03.849

Alawi, T. O. (2016). The social and affective dimensions of early second language acquisition: A case study. International Journal of Education and Research, 4(5), 1324.

Albalawi, B. R. (2014). Effectiveness of teaching english subject using drama on the development of students' creative thinking. IOSR Journal of Research \& Method in Education (IOSR-JRME), 4(6), 54-63. https://doi.org/10.9790/7388-04615463

Carrió-Pastor, M. L., \& Mestre, E. M. M. (2014). Motivation in second language acquisition. Procedia - Social and Behavioral Sciences, 116(2002), 240-244. https://doi.org/10.1016/j.sbspro.2014.01.201

Carter, N., Bryant-Lukosius, D., DiCenso, A., Blythe, J., \& Neville, A. J. (2014). The use of triangulation in qualitative research. Oncology Nursing Forum, 41(5), 545-547. https://doi.org/10.1188/14.onf.545-547

Cocca, M., Pérez García, J. A., Zamarripa, J. I., Demetriou, Y., \& Cocca, A. (2017). Psychometric parameters of the attitude/motivation test battery instrument in a Mexican environment. Revista de Psicologia Del Deporte, 26, 149-155.

Creswell, J. W. (2012). Educational research: Planning, conducting, and evaluating quantitative and qualitative research ( $4^{\text {th }} \mathrm{ed}$.). Pearson Education.

Crystal, D. (2003). English as a global language (2nd ed.). Cambridge University Press.

De Costa, P. I. (2009). English as an international language: Perspectives and pedagogical issues. World Englishes, 28(4), 552-563. https://doi.org/10.1111/j.1467971x.2009.01612.x

Flanigan, B. O. (1991). Peer tutoring and second language acquisition in the elementary school. Applied Linguistics, 12(2), 141-158. 
https://doi.org/10.1093/applin/12.2.141

Francis, N., \& Ryan, P. M. (1998). English as an International language of prestige: Conflicting cultural perspectives and shifting ethnolinguistic loyalties, 29(1), 25-43. https://doi.org/10.1525/aeq.1998.29.1.25

Gardner, R. C. (1985). Social psychology and second language learning: The role of attitudes and motivation. Social Phsycology and Second Language Learning.

Gardner, R. C. (2004). Attitude/motivation test battery: International AMTB research project. The University of Western Ontario.

Ghazvini, S. D., \& Khajehpour, M. (2011). Attitudes and motivation in learning English as second language in high school students. Procedia - Social and Behavioral Sciences, 15, 1209-1213. https://doi.org/10.1016/j.sbspro.2011.03.264

Gonzales, R.., \& Lopez, M. (2015). Foreign language learning motivation questionnaire: Further examination of a six - factor model.

Greenfader, C. M., Brouillette, L., \& Farkas, G. (2015). Effect of a performing arts program on the oral language skills of young English learners. Reading Research Quarterly, 50(2), 185-203. https://doi.org/10.1002/rrq.90

Guion, L. A., Diehl, D. C., \& Mcdonald, D. (2002). Triangulation: Establishing the validity of qualitative. University of Florida/IFAS, 1-3. https://doi.org/10.32473/edis-fy394-2011

Iamsaard, P., \& Kerdpol, S. (2015). A study of effect of dramatic activities on improving English communicative speaking skill of grade 11 th students. English Language Teaching, 8(11), 69. https://doi.org/10.5539/elt.v8n11p69

International Hospitality Research Centre Switzerland. (2016). Trustworthiness in qualitative data collection and analysis. https://www.ihrcs.ch/?p=1228

Javid, C. Z. (2013). An Investigation of Effectiveness of Simulation in Developing Oral Skills : a Case Study, 9(32), 254-270.

Dewaele, J. M., \& MacIntyre, P. D. (2016). Foreign language enjoyment and foreign language classroom anxiety: The right and left feet of the language learner. Positive psychology in SLA, 215, 236. https://doi.org/10.21832/9781783095360-010

Employers: Fresh graduates have unrealistic expectations. (2015, December 8). JobStreet Malaysia. Retrieved from https:/www.jobstreet.com.my/careerresources/employers-fresh-graduatesunrealistic-expectations/

Kalidas, C. S. (2014). Drama: A tool for learning. Procedia - Social and Behavioral Sciences, 123, 444-449.

https://doi.org/10.1016/j.sbspro.2014.01.1443
Krashen, S. D. (1982). Principles and practice in second language acquisition. Pergamon Press.

Lee, E.-H., \& Oh, H.-J. (2011). Relationship between motivation and proficiency improvement. Linguistic Research, 28(2), 405430.

https://doi.org/10.17250/khisli.28.2.201108.00 9

Nawi, A. M. (2014). Applied drama in English language learning. University of Canterbury.

Mahadi, T. S. T., \& Jafari, S. M. (2012). Motivation, its types, and its impacts in language learning. International Journal of Business and Social Science, 3(24), 230-235.

Malay Mail Online. (2016, December 22). Jobstreet: Unrealistic salary demands reason why fresh grads are unemployed. http://www.themalaymailonline.com/malaysia/ article/jobstreet-unrealistic-salary-demandsreason-why-fresh-grads-areunemployed\#S11 JyrriJ6hB2REO.97

Man, C. F., May, A. L. J., Sharif, S., \& Singh, S. S. B. (2019). Exploring the use of drama-based activities as a learning tool in English oral proficiency development among students from non-Malay medium nation schools: A preliminary study. International Journal of Academic Research in Business and Social Sciences, 9(6), 1202-1215. https://doi.org/10.6007/ijarbss/v9-i6/6082

$\mathrm{Ni}, \mathrm{H}$. (2012). The effects of affective factors in SLA and pedagogical implications. Theory \& Practice in Language Studies, 2(7), 15081513. https://doi.org/10.4304/tpls.2.7.15081513

Nordin, N. A., Sharif, N. M., Fong, N. S., Mansor, W. F. A. W., \& Zakaria, M. H. (2012). Fulfilling the Tasks of Reading, Writing, Speaking and Listening through Drama Workshop. Procedia - Social and Behavioral Sciences, 66, 196-202. https://doi.org/10.1016/j.sbspro.2012.11.261

Nunan, D. (2001). English as a global language. TESOL quarterly, 35(4), 605-606. https://doi.org/10.2307/3588436

Nzanana, J. B. (2016). Language learning motivation and oral proficiency in learners of English as a foreign language: The case of university students in Rwanda. Michigan State University.

Orío, S. F. (2013). Motivation and second language acquisition. Servicio de Publicaciones: Grado en Estudios Engleses.

Papadopoulos, I. M. (2014). The dramatization of children literature books for the development of the second/foreign language: An implementation of a drama-based project to students of primary school, 2(2), 188-206. https://doi.org/10.22158/selt.v2n2p188

Rew, S., \& Moon, Y. I. (2013). The effects of using 
English drama on the learning of target expressions for primary school students. Journal of Asia TEFL, 10(4), 215-239.

Samad, A. A., Etemadzadeh, A., \& Far, H. R. (2012). Motivation and language proficiency: Instrumental and integrative aspects. Procedia - Social and Behavioral Sciences, 66, 432-440. https://doi.org/10.1016/j.sbspro.2012.11.287

Saville-Troike, M. (2006). Introducing second language acquisition. Cambridge University Press.

Schutz, P. A., \& Pekrun, R. (Eds.). (2007). Emotion in education. Academic Press.

Shenton, A. K. (2004). Strategies for ensuring trustworthiness in qualitative research projects. Education for Information, 22(2), 63-75. https://doi.org/10.3233/efi-2004-22201

Smet, D. D. (2016). Motivation and Second language acquisition: A study on the relation between motivation and oral proficiency [Bachelor's thesis].

Smit, U. (2010). English as a lingua franca in higher education: A longitudinal study of classroom discourse. World Englishes, 32(2), 289-292. https://doi.org/10.1111/weng. 12028

Tavares, V. (2016). The Role of peer interaction and second language learning for esl students in academic contexts: An extended literature review. http://hdl.handle.net/10315/34200

Thornton, K. (2015). The Crucial Role of PeerLearning in Language Learning Spaces, Studies in Self-Access Learning Journal, 6(3), 286-287. https://sisaljournal.org/archives/sep15/thornton

Trinity College London. (2009). Communication skills: Graded exams and professional certificates. Syllabus from 2010.

Wimolmas, R. (2012). A survey study of motivation in English language learning of first year undergraduate students at Sirindhorn international institute of technology (SIIT), Thammasat university. FLLT Conference Proceedings by LITU, 2(1), 904-915. 